\title{
Terms of geometric action of rotating ball follower
}

\author{
Maciej Kuchar \\ Lodz University of Technology, 90-424 Lodz, Zeromskiego 116, Poland, E-mail: kucharma@p.lodz.pl
}

crossref $\mathrm{http}: / / \mathrm{dx}$.doi.org/10.5755/j01.mech.20.6.7419

\section{Introduction}

Special welding machine for producing the building grid with PVC covered glass roving [1] was developed (Fig. 1) by thermal method. The grid is formed weaveless on a rotating drum where the welding is performed. The rotation of the drum is obtained by electrical motor. The grid before welding is stretched on special pegs provided for this purpose. The location of the pegs on the drum is made evenly and comparatively densely to their diameters for technological reason. In order to get a reliable hooking up of the roving during stretching, the pegs at a defined location on the drum are lifted up and than withdrawn. The lifting up of the pegs is carried out by means of rotating ball followers [2]. The followers are rotating on rigid axis. The withdraw of the pegs to the start up position is achieved by a spring. The solution of the problem of the uplift of the pegs using the rotating follower seems to be simple and cheap ensuring reliable operation [3]. The need for preparation an additional tapered slot in the pegs (Fig. 4) slightly increases the cost.

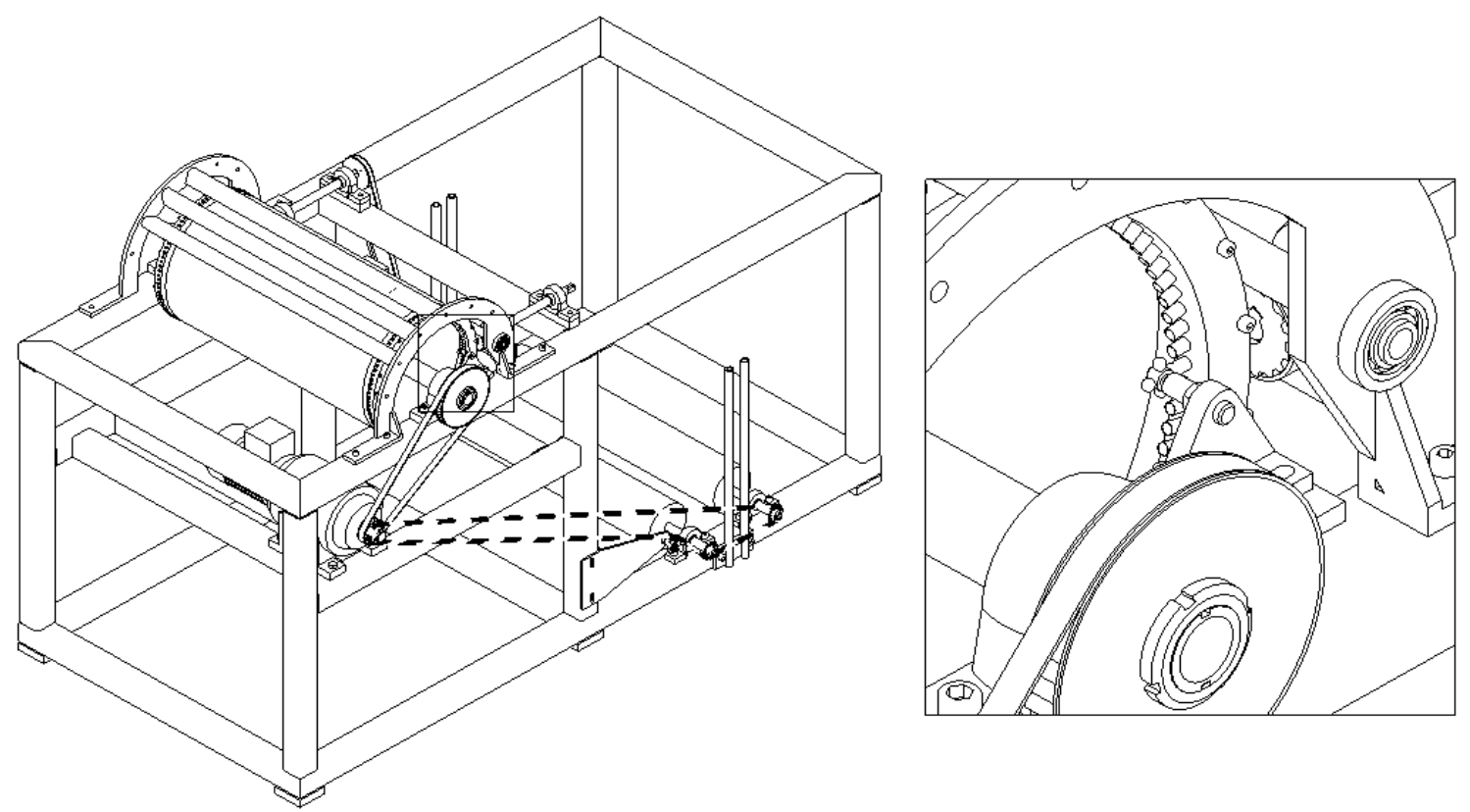

Fig. 1 The welding machine for glass roving grid

\section{Description of operation of the rotating ball follower}

The operation of the rotating ball follower is shown in Fig. 2. The rotary motion of the follower (angular velocity $\omega_{p}$ ) is provided by cooperation between the spherical surfaces 1 and the tapered slots of the lifted up pegs 3 . The synchronic action of the follower does not require a coupling with the drive axle of the drum 4 . The follower is embedded in a rigid axel 2 attached to the frame of the welding machine and has the ability to self positioning in the plain of the pegs. Relatively constant thrust of the pegs on the follower during the action is provided by the coil springs 5 .

For technical reason, large uplift $w_{\max }$ of densely located pegs relatively to the spacing $t_{k}$ has been applied. The maximum uplift of the peg is understand as its peak dislocation during the interacting stage with the follower.
The value of uplift of nearly the half of the spacing of the pegs was assumed.

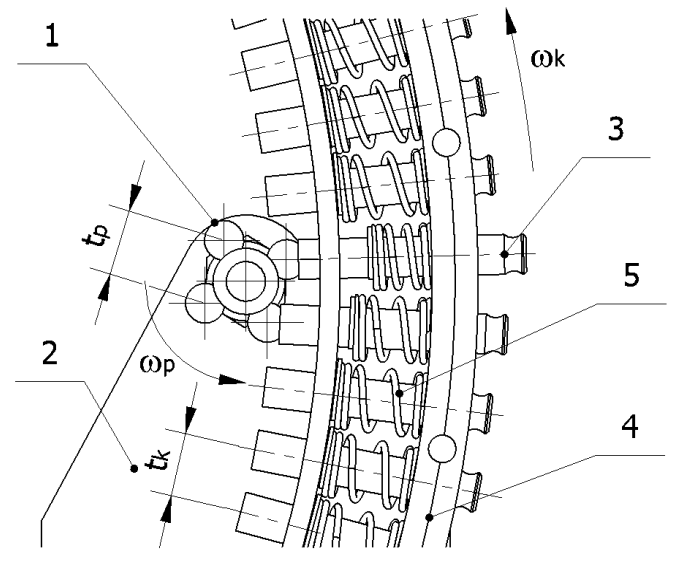

Fig. 2 Rotating ball follower 


\section{Simulation model of the operation of the rotating ball follower}

Dynamical model of the rotating ball follower was worked out to carry out simulation research [4-7]. The model shown schematically in Fig. 3 assumes standing parameters: springs rate $k=5 \mathrm{~N} / \mathrm{mm}$ and its initial tension, friction factors of peg against drum's hole, follower on its axle, the ball of the follower against the tapered slot of the peg $\mu=0.1$, the belt force of roving acting on an individual peg $P_{N}=0.2 \mathrm{~N}$, angular velocity of the drum $\omega_{k}=0.5 \mathrm{rad} / \mathrm{s}$.

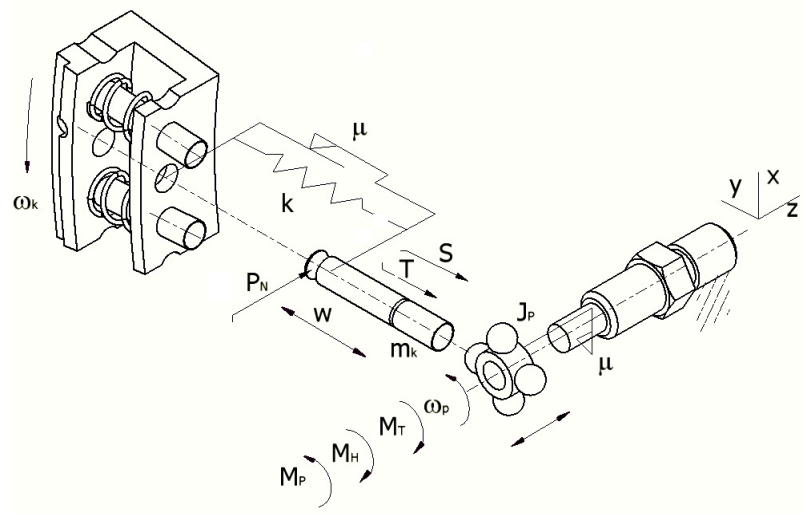

Fig. 3 Dynamical model of operation of the rotating ball follower

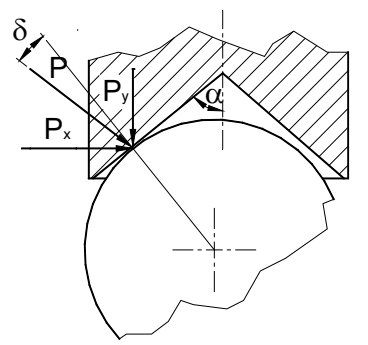

Fig. 4 Acting of the tapered slot of the peg on the ball of the follower

The force impacting between the ball of the follower and the tapered slot in the peg $P$ (considering the friction angle $\delta$ ) and the force components $P_{x}$ and $P_{y}$ have been presented in the Fig. 4. Taking the denotations in Figs. 3 and 4 into consideration, the equation for the uplift of the peg is:

$$
m_{k} \ddot{w}=P_{y}-S-T,
$$

where $S$ is the acting force of the spring on the peg, $T$ is the friction force of the peg against the hole of the drum.

The equation of motion of the rotating follower is:

$$
J_{p} \dot{\omega}_{p}=M_{P}-M_{T}-M_{H},
$$

where $M_{P}$ is driving torque of the follower, $M_{H}$ is additional braking torque, $M_{T}$ is dry friction moment of the follower.

Values the components of the Eqs. (1) and (2) depend mainly on the rotational angle of the follower. Relating to such angle, the follower can cooperate with one or two pegs at the same time. The relationships between val- ues of mentioned components and geometrical and dynamic parameters of the model have not been presented, due to their high complexity. Such values can be obtained iteratively using the inner algorithm of the Dynamic Simulation Module included in the Autodesk Inventor 2009 Professional software $[8,9]$. Using such a software, it has been curried out simulation tests of the rotating ball follower. An example of instantaneous value of spring force $S$ acting on the peg and dry friction force $T$ acting between the peg and drum's hole during a single cycle of uplifting of the peg is shown in Fig. 5.

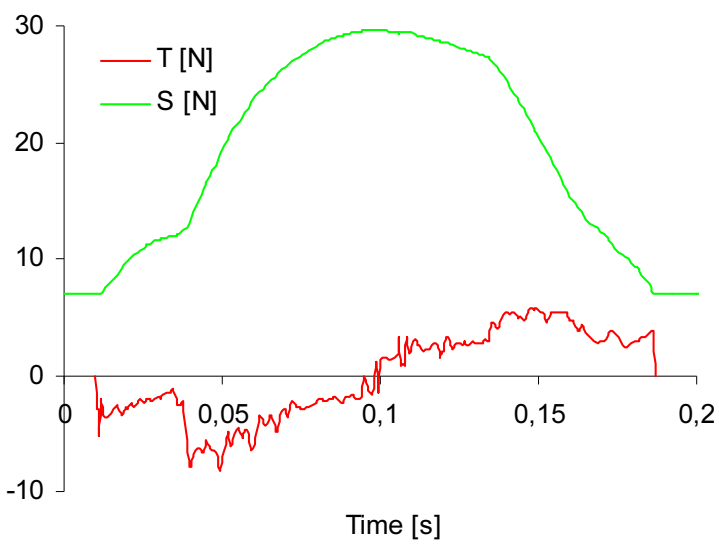

Fig. 5 Instantaneous values of spring force and dry friction force acting on the peg $\left(t_{p} / t_{k}=1.01 ; w_{\max } / t_{k}=0.47\right.$; $\alpha=45$ )

In the course it is visible the change in the sense of friction force related to the phases of uplift and withdraw. It is also presented the cooperate phase of the follower with the one peg. Samples of instantaneous values of dry friction moment $M_{T}$ of the follower on the rigid axle are shown in Fig. 6.

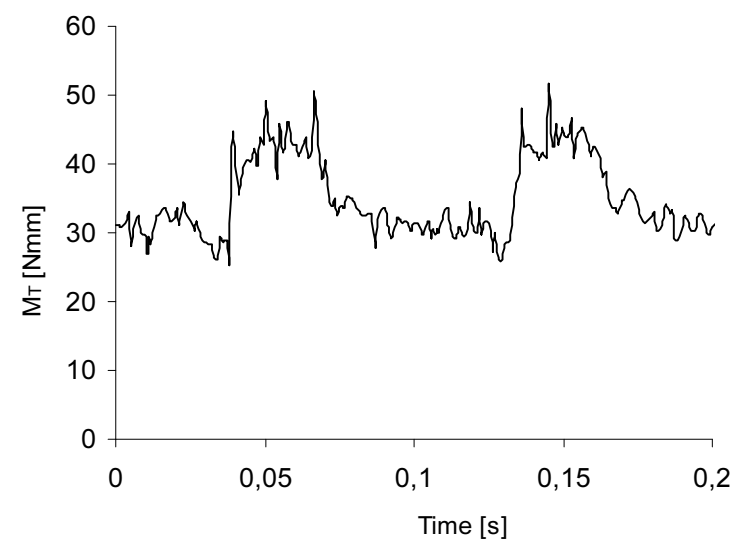

Fig. 6 Instantaneous values of dry friction moment of the follower on the axle $\left(t_{p} / t_{k}=1.01 ; w_{\max } / t_{k}=0.47\right.$; $\alpha=45$ )

In the course of the dry friction moment it is visible the phases of co-operation the follower with one and with two pegs. The value of the friction moment increases about $20 \%$ in the phase of co-operation the follower with two pegs, at the same time.

\section{Results of the simulation tests}

During analysis the co-operation of the follower and the pegs, it is necessary to consider the slippages of the 
ball on the tapered slot and also the periodic change of the sense of the component $P_{x}$ of the force $P$ acting between the peg and the ball of the follower (Fig. 4). It results in an uneven run of the angular velocity of the follower during the uplifting cycle. It can be important in the relation to the other applications of rotational ball follower than this described in the article. Taking the similarity with a toothed gear into consideration the action of the follower does not fulfill the essential Willis meshing law [10]. Examples of instantaneous value of angular velocity of the follower $\omega_{p}$ are shown in Fig. 7. The instantaneous values of velocity may differ from mean value even twice.

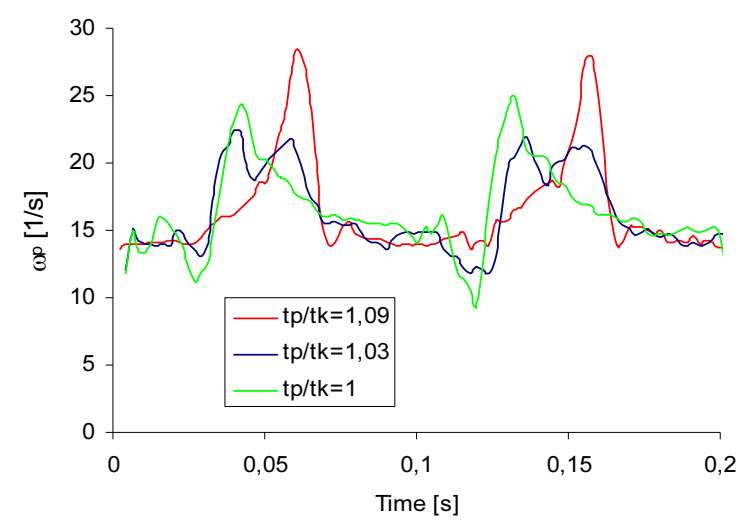

Fig. 7 The instantaneous values of angular velocity for different relative spacing of the follower balls $\left(w_{\max } / t_{k}=0.47 ; \alpha=45^{\circ}\right)$

The reason of the analysis of the angular velocity of the follower was to determine the average velocity $\omega_{p s r}$ of the cycle and standard deviation from average values $\sigma$ for different relative spacing of the balls of the follower. The results of the analysis of the angular velocity are shown in Fig. 8.

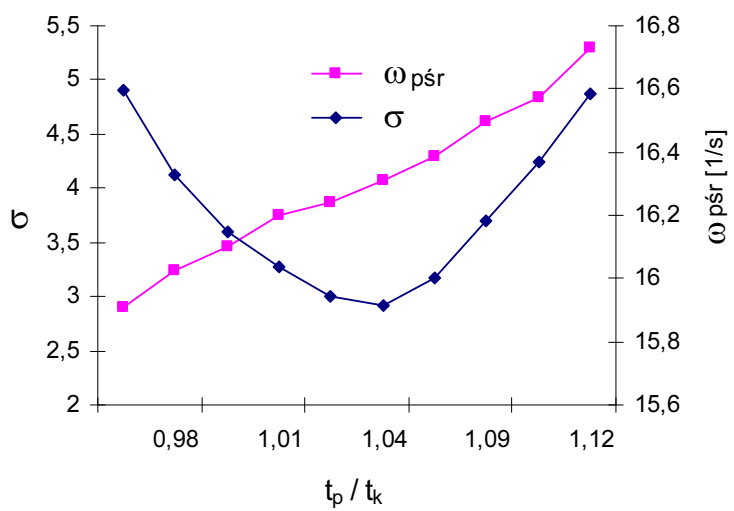

Fig. 8 Standard deviation of the angular velocity and average angular velocity of the follower vs. relative spacing of the follower balls

The follower rotates more evenly within a certain range of a relative spacing of the balls. The standard deviation of the angular velocity of the follower $\sigma$ assumes its lowest values in the range of $t_{p} / t_{k}=1.0-1.06$. Also on that range on the runs (Fig. 7) a double jump of instantaneous values of velocity was noticed.

At further stage the values of geometrical parameters as ball spacing $t_{p}$, maximum uplifting of the peg $w_{\max }$ and angle of a tapered slot $\alpha$ were introduced to guarantee correct operation of the rotating ball follower. An additional braking moment $M_{H}$ was introduced into Eq. 3 to determine the best and limiting values of these parameters. It was described highest value that does not yet result in falling out of the spherical surfaces of the followers out of the tapered slots of the pegs. The action of the follower in the range of one cycle was analyzed. The value of the braking moment vs. the relative spacing of the balls of the follower for different angles $\alpha$ of the tapered slot of follower are shown in Fig. 9.

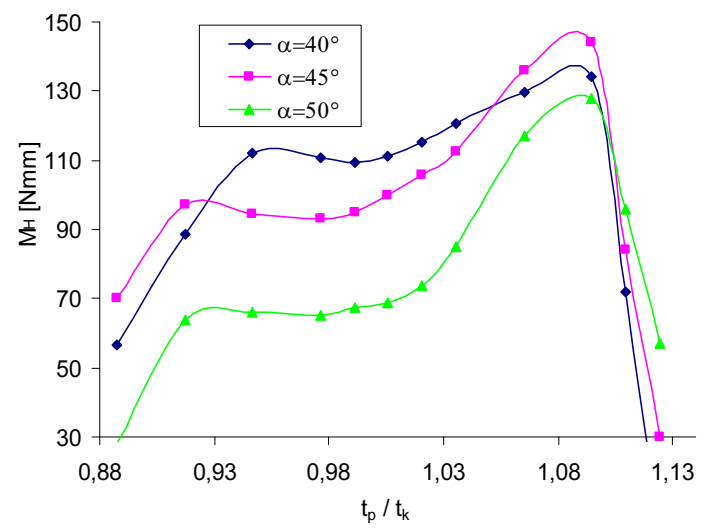

Fig. 9 The highest value of braking moment of the follower vs. relative spacing of the follower balls $\left(w_{\max } / t_{k}=0.5\right)$

There exist optimal ranges of relative spacing $\left(t_{p} / t_{k}=0.93-1.0\right)$ at which the additional braking moment $M_{H}$ acting on the follower is the largest. The influence of the largest uplifting $w_{\max }$ in relation with the peg's spacing $t_{k}$ on the value of the braking moment is shown in Fig. 10.

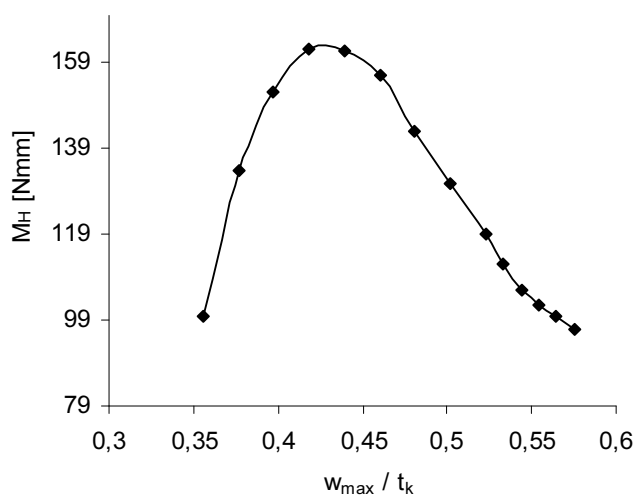

Fig. 10 Braking moment of the follower vs. relative uplifting of the peg $\left(t_{p} / t_{k}=1.07 ; \alpha=45^{\circ}\right)$

There exist a range of relative uplifting of the peg $\left(w_{\max } / t_{k}=0.4-0.5\right)$ at which the braking moment acting on the follower is the largest. The indicated optimum ranges of the ball spacing and uplifting of the pegs guarantee the proper operation of the follower.

\section{Experimental verification of the operation of the ro- tating ball follower}

The rotating ball follower was made and its action was verified. The assembly of welding drum along with the pegs and the set of the rotating ball follower is shown in Fig. 11. The follower was made under the assumption 
that the value of relative spacing lies in the optimal range $\left(t_{p} / t_{k}=1.06\right)$. The follower and the pegs were made of alloy steel $41 \mathrm{Cr} 4$ quenched and tempered achieving hardness in the rage 47-52 HRC. The appropriate choice of thermal resisting grease and high demands on the state of interacting surfaces $(R a 0.04)$ caused a decrease of the friction forces and the noise [11-13].

Correct operation of the follower throughout the full range of the anticipated angular velocity of the drum

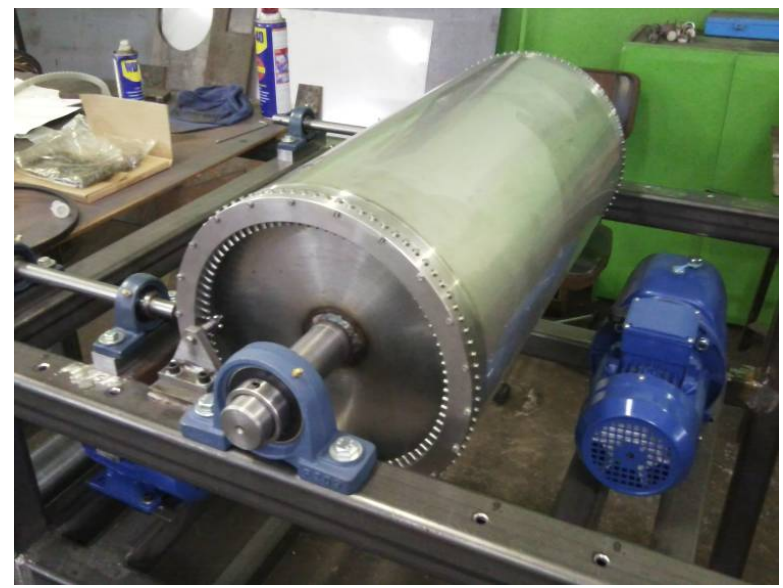

a

Fig. 11 Welding machine drum's set (a); rotating ball follower's set (b)
(1-10 rev/min). The occurring then maximum values of the relative uplifting the pegs have been in the range of $\left(w_{\max } / t_{k}=0.4-0.5\right)$ referred to as the optimal one specified in the chapter 4 . The uplifting of the pegs as well as the self positioning of the follower in the plain of the pegs proceeded smoothly. The noise level generated by operating of the follower is to be neglected in regard to the noise genereted by the operating welding machine.

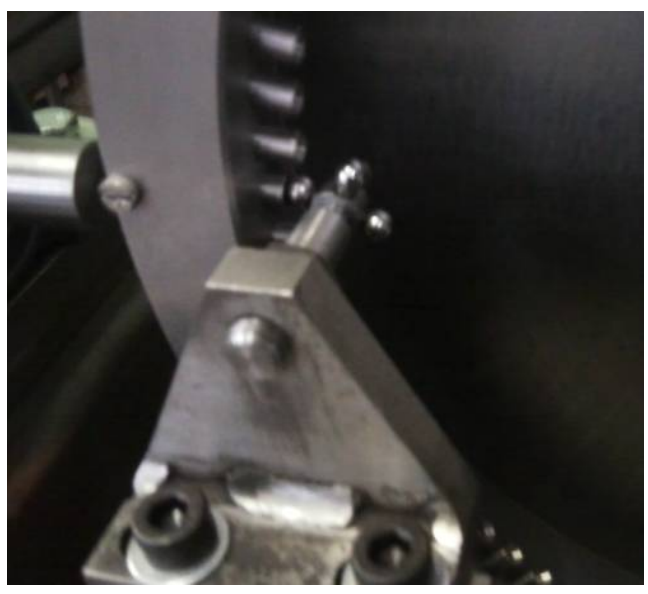

b

\section{Conclusions}

1 There exist some range of the relative spacing of the balls at which optimal operation of the follower is ensured, it amounts to $t_{p} / t_{k}=0.93-1.10$.

2. There exist a range of a relative uplifting of the peg where the additional braking moment that acts on the follower is the largest and equals $w_{\max } / t_{k}=0.4-0.5$.

3 The optimal, for transmitted by the follower moment, angle of the tapered slot in the pegs is $\alpha=45^{\circ}$.

4 . The follower rotates more evenly within a certain range of a relative spacing of the balls $t_{p} / t_{k}=1.0-1.06$.

5 The followers are working properly, ensuring fault save uplifting of the pegs.

\section{References}

1. Kuchar, M.; Podsiedlik, W.; Słodowy, J.; Wiśniewski, M. 2011. The method of generating the new weaveless textile structures, Maintenance Problems 4/2011: 195-204'

2. Kuchar, M.; Podsiedlik, W.; Wiśniewski, M. 2014. The rotating ball follower. Patent nr P394865 Patent Office of Republic of Poland.

3. Bara, M.; Stan, S.-D.; Teutan, E.; Verdes, D. 2009. Design and virtual reality imulation of frontal - sinusoidal ball transmission, Mechanika 4(78): 63-67.

4. Alaci, S.; Ciornei, F.C.; Filote, C. 2013. Considerations upon a new tripod joint solution, Mechanika 19(5): 567-574.

http://dx.doi.org/10.5755/j01.mech.19.5.5539.

5. Augustaitis, V.K.; Gičan, V.; Šešok, N.; Iljin, I. 2011. Computer-aided generation of equations and structural diagrams for simulation of linear stationary mechanical dynamic systems, Mechanika 17(3): 255263.

http://dx.doi.org/10.5755/j01.mech.17.3.500.

6. Rat, N.R.; Neagoe, M.; Diaconescu, D.; Stan, S.D. 2011. Dynamic simulations regarding the influence of the load-rigidity correlation on the working accuracy of a medical Triglide parallel robot, Mechanika 17(2): 178-181.

http://dx.doi.org/10.5755/j01.mech.17.2.336.

7. Bakšys, B.; Sokolova, T. 2009. Mutual positioning of automatically assembled noncylindrical parts, Mechanika 2(76): 38-45.

8. Kuchar, M. 2013. Vibratory thickening of weft threads in a weaving loom - simulation tests, Fibres \& Textiles in Eastern Europe; 21, 5(101): 59-64.

9. Kuchar, M. 2013. The vibration beat-up in the weaving loom. Lodz University of Technology.

10. Jaśkiewicz, Z.; Wąsiewski, A. 1992. Cylindrical gears. WKL, Warsaw.

11. Augustaitis V. K.; Bučinskas V. 2011. Dependency of bearing noise properties on surfaces lubrication, Mechanika 17(4): 381-386. http://dx.doi.org/10.5755/j01.mech.17.4.566.

12. Płaza, S.; Magielewski, L.; Celichowski, G. 2005. Introduction to tribology. University of Lodz.

13. Bhushan, B. Modern Tribology Handbook. Crc Press, 2001-1690. 
Maciej Kuchar

\section{BESISUKANČIO RUTULINIO SEKIKLIO \\ GEOMETRINĖS SĄVEIKOS PARAMETRAI}

Reziumè

Straipsnyje pateikiamas naujos konstrukcijos besisukančio rutulinio sekiklio veikimas. Parinktų geometriniu parametrų įtaka analizuojama modeliavimo būdu. Nustatytos šių parametrų intervalai užtikrinantys tinkamą sekiklio darbą. Besisukančio rutulinio sekiklio veikimas patikrintas realiose sąlygose.
Maciej Kuchar

TERMS OF GEOMETRIC ACTION OF ROTATING BALL FOLLOWER

Su m m ary

The operation of a new rotating ball follower is presented. The influence of the values of the selected geometrical parameters of the rotating ball follower by simulation are analyzed. The ranges of value of these parameters ensuring correct operation of the rotating ball follower are defined. The operation of the rotating ball follower in real conditions are verified.

Keywords: rotating ball follower, pegs, drum, dynamical model, dry friction force, dry friction moment.

Received May 27, 2014

Accepted November 17, 2014 